\title{
Ecos del tiempo subterráneo. Las peñas en Santiago durante el régimen militar (1973-1983)*
}

Gabriela Bravo Chiappe y Cristian González Farfán

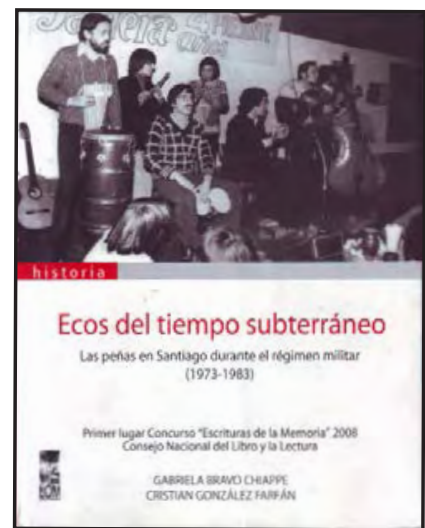

Cristian Yáñez AgUilaR ${ }^{\star *}$

Las peñas fueron un espacio de expresión y simbolismo asociado a intelectuales y artistas de izquierda hacia fines de los años sesenta y durante los años del gobierno de la Unidad Popular. Algunas de ellas, como el caso de la pionera "Peña de los Parra", se transformaron en ícono de un período caracterizado por una canción de denuncia

* 2009. Santiago: Lom Ediciones. 217 páginas.

*** Instituto de Comunicación Social, Facultad de Filosofía y Humanidades. Universidad Austral de Chile, Isla Teja s/n. E-mail: cyanezaguilar@gmail.com. 
y protesta que, en el espacio urbano, se vistió de sonidos y una estética asociados al mundo andino -quenas, charango, mantas- que reivindicaban la unidad latinoamericana. Fue en este período en que la Nueva Canción Chilena, junto a diversas expresiones como el muralismo y el cine documental, florecieron de la mano de un contenido social que se apagó con la llegada de los militares al poder, la proscripción de los partidos políticos y la prohibición de cualquier práctica de esta índole.

Si bien existe conocimiento respecto al rol que tuvieron las peñas durante el período anterior a la dictadura, poco se ha escrito sobre aquellas que funcionaron durante el tiempo de mayor represión política hacia los partidarios de izquierda. En este sentido, el libro de los periodistas Gabriela Bravo y Cristian González constituye un aporte importante a la recuperación de la memoria histórica relativa a las peñas de Santiago durante los primeros 10 años del Gobierno Militar. El libro se aboca a un tipo de práctica que califican como "negada", y donde buena parte de sus gestores fueron quienes se quedaron en Chile mientras otros partían al exilio. En este contexto, destaca el prólogo escrito por el fallecido Premio Nacional de Periodismo, José Miguel Varas.

El texto fue elaborado por periodistas de la Universidad de Santiago, y resultó ganador del concurso Escrituras de la Memoria organizado por el Consejo Nacional de la Cultura y las Artes, razón por la que alcanzó difusión y fue publicado por LOM Ediciones. Lo anterior resulta relevante debido a que -dada la formación de los autores- construyen un libro fundado en los testimonios de músicos, dueños de locales y público que alguna vez asistió a estos encuentros. Dichos relatos son matizados con reflexiones sociológicas que explican, desde una perspectiva más amplia, el período al que refieren las fuentes vivas.

En términos formales, podríamos calificar el libro dentro del ámbito del Periodismo de Investigación, puesto que se vale de herramientas cualitativas que permiten indagar en profundidad el fenómeno expuesto de acuerdo a la delimitación geográfica y temporal que consideran los autores. El que se trate de una publicación en clave periodística también es interesante, puesto que está escrito mediante códigos que facilitan una lectura rápida y atractiva donde el contexto de la época y cada uno de los aspectos abordados se enriquece con las voces de sus protagonistas.

Bravo y González distribuyen el texto en tres grandes etapas que, a su vez, se subdividen en 12 capítulos. A grandes rasgos, la primera parte 
sirve como contextualización histórica. En la segunda etapa desarrollan el tema de las peñas, la represión formal, informal, aspectos artísticos y sociales, para finalmente abordar el ocaso de este tipo de actividades ya en la década de los años 80 . De acuerdo a los autores, este ocaso se vincula con un una nueva época en que comienzan a consolidarse transformaciones económicas que posteriormente darán lugar a una configuración social en que la peña irá perdiendo su poder de espacio aglutinante para un grupo de personas. De este modo, las acciones de resistencia comenzaron a canalizarse mediante diversas tribunas lo que -sumado a otros factores- precipitó el cierre de estos espacios y el fin de varias peñas que venían funcionando desde la década anterior.

Los autores no sólo conciben la Peña Alternativa como un medio de difusión y creación artística, sino como un espacio de comunicación grupal donde se comparten elementos significativos asociados a las ideas acalladas por la represión. "Asumiendo que la prensa de izquierda está amordazada y que la represión se intensifica con mayor crudeza, la peña, a través de sus componentes, de la información que circula, del repertorio de los cantores, y del cúmulo de símbolos que representa, se alza como un espacio donde artistas y públicos median determinadas situaciones" (2009: 68).

Desde una perspectiva taxonómica, proponen tres criterios de clasificación que son desarrollados a lo largo del texto. En primer lugar y de acuerdo a su constitución geográfica, distinguen entre peñas establecidas, universitarias y poblacionales o sindicales; de acuerdo al lugar de funcionamiento, entre aquellas que trabajaban bajo el alero de restaurantes, peñas restaurantes (funcionaban bajo la lógica de 'comida a la carta') y aquellas con recinto propio; por último, según un criterio político, clasifican entre: peñas comprometidas políticamente, peñas 'blancas' y peñas no comprometidas políticamente.

Fue así como ante un modelo hegemónico que volvía sobre el denominado Canto Típico de los años 20, el discurso de la alta cultura y la consolidación de una industria televisiva, radial y discográfica basada en música desechable y apolítica, las peñas fueron el espacio donde se recluyó el canto social. En principio, fue allí donde se pudieron revivir aspectos vinculados a la estética de la Nueva Canción Chilena. En un segundo momento, las peñas se vincularon al Canto Nuevo y la enorme riqueza literaria que se produjo -entre otras cosas- a causa del uso forzado de la metáfora, debido al hostigamiento permanente por 
parte de la policía uniformada y los infiltrados que pertenecían a las unidades de inteligencia.

Los casos se abordan en el libro con una vivacidad narrativa a través de relatos que describen situaciones concretas. Un ejemplo de ello es el recuerdo de un cantor guitarrista que durante algún tiempo fue artista de peña y que resultó ser un infiltrado. Era la época en que el sólo hecho de decir que se interpretaría una canción de Víctor Jara-aunque ésta careciera de contenido político- arrancaba los aplausos de una audiencia cuya opinión estaba silenciada. De este modo, como apunta Jorge Venegas del Dúo Semilla, "si se hablaba de dictadura, decíamos invierno; y si se halaba de la esperanza, de salir de la atrocidad que se estaba cometiendo, decíamos primavera" (2009: 143).

Quizás uno de los fragmentos más sugerentes del libro corresponde a la muestra de archivos fotográficos donde aparecen en escena personajes como el comunicador Miguel Davagnino, Ricardo García del sello Alerce, el grupo Chamal, la intérprete conocida como Capri, Eduardo Peralta, Roberto Parra, Catalina Rojas, Jorge Yáñez, Gabriela Pizarro y tantos otros que participaron de las peñas. Mediante un acopio testimonial exhaustivo el libro desmiente la tesis del apagón cultural tan difundido en aquella época por los medios oficiales, al mismo tiempo que aborda el tratamiento negativo que recibían las peñas por parte de la prensa de derecha.

Sin duda se trata de un momento opaco del pasado reciente, donde incluso Tilusa -quien actuó por años junto a Francisco Caucamán en la peña Casa Kamarundi- fue conocido como El Caballero del Humor Triste. El libro-reportaje logra un tratamiento equilibrado entre los aspectos anecdóticos y el contexto socio-histórico. En definitiva, se le otorga un valor a la memoria histórica cuya impronta se hace otra vez vigente en la actualidad y se vuelve resistente, ante un escenario en el cual el modelo económico tiende sistemáticamente al olvido, con el fin de modelar una sociedad que sea afín a su propia lógica. 